\title{
Association of Age and Gender Distribution of Patients Undergoing Root Canal Treatment in Maxillary Anteriors
}

\author{
S.G.Vishnu Prasanna ${ }^{1}$ S. Haripriya ${ }^{2 *}$ and S. P. Saravana Dinesh ${ }^{3}$ \\ ${ }^{1,2}$ Department of Conservative Dentistry and Endodontics, Saveetha Dental College, \\ Saveetha Institute of Medicine and Technical Sciences, Chennai - 600077 Tamilnadu, India \\ ${ }^{3}$ Department of Orthodontics, Saveetha Dental College, Saveetha Institute of \\ Medicine and Technical Sciences, Chennai - 600077, India \\ Corresponding author email: harpriyas.sdc@saveetha.com
}

\begin{abstract}
Aim of the study was to find the association of age, gender and teeth distribution in patients undergoing root canal treatment in maxillary anteriors. This study was conducted at a private dental institute between June 2019 to March 2020. 86000 patient records were analysed. A total of 988 patients who underwent root canal treatment in 1753 maxillary anteriors were evaluated. Data collection was done and the results were tabulated in excel sheet. Obtained results were statistically analysed with SPSS software. From the results it was observed that, Maximum number of maxillary anterior root canal treatments was done in the age group of below 30 years $(51 \%)$ and the least being patients above 60 years (6\%). Male patients $(52.94 \%)$ and female patients $(47.06 \%)$ had undergone root canal treatment for maxillary anteriors. Maximum number of root canal treatment was done in $11(23.5 \%)$ and the least was 13 (10.33\%).Association between age of the patients and number of patients undergoing root canal treatment in maxillary anteriors, revealed that most of the root canal treatment was done in the age group of below 30 years, teeth commonly involved was 11 and the least was patients above 60 years in $21(0.91 \%)(\mathrm{p}<0.05)$ hence statistically significant. Association between gender of the patient and number of patients undergoing root canal treatment in maxillary anteriors revealed that most of the root canal treatment was done in male patients pertaining to tooth number $21(13.94 \%)$ and the least being 23 in male patients $(4.16 \%)(\mathrm{p}<0.05)$ hence statistically significant.
\end{abstract}

\section{KEY WORDS: AGE, GENDER, ROOT CANAL TREATMENT, MAXILLARY ANTERIORS.}

\section{INTRODUCTION}

Dental caries is the most common cause for the loss of enamel in a clinical situation. Dental caries is easily detectable and reversible at an early stage Root canal treatment is an endodontic treatment which is used to save a tooth that has been infected due to caries. The main objective of performing root canal therapy was to eliminate bacteria from the infected root canal system or remove inflamed pulp tissue and close it with a biologically acceptable filling material. The reasons for undergoing root canal treatment in maxillary anteriors are generally tooth with dental caries

Biosc Biotech Res Comm P-ISSN: 0974-6455 E-ISSN: 2321-4007
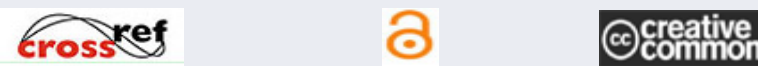

Identifiers and Pagination

Article Information

Year: 2021 Vol: 14 No (10) Special Issue

Pages: 104-108

Received: $19^{\text {th }}$ Aug 2021

This is an open access article under Creative

Commons License Attribn 4.0 Intl (CC-BY).

DOI: $h t t p: / / d x . d o i . o r g / 10.21786 / b b r c / 14.10 .17$ with pulpal involvement, non-vital teeth, trauma, ellis class III fracture, non-carious lesions. Intentional root canal treatments are also performed in the anteriors as there is a high chance of pulpal exposure due to excessive tooth preparation.

The steps in root canal treatment involve access cavity preparation, cleaning and shaping, biomechanical preparation, obturation, coronal seal, crown cementation. One important step in root canal treatment is to find, clean and disinfect all root canals. Knowledge about variations of the root canal system of all teeth directly affects the outcome of endodontic treatment. Reasons that leading to endodontic failure involves diagnostic errors, persistence of the infection, errors in debridement, cleaning and shaping of root canal systems, instruments fractures and poor restorations (Setzer et al., 2011; Al-Rahabi and Abdulkhayum, 2012; Arya et al., 2018; Rajendran et al., 2019).

Pulp vitality tests are the valuable diagnostic tool which aids the clinician towards the accurate diagnosis and appropriate

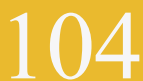


treatment planning. Diagnosing the exact pulpal status by direct examination is uncertain due to the fact that the pulp is enclosed within a hard tissue. Once proper diagnosis is done, the tooth is prepared for root canal treatment. The first step is to provide local anesthesia to the affected tooth and the next step will be isolating the affected tooth with a rubber dam. Then the access cavity is prepared. The diseased pulp is removed by practitioners through access cavity preparation and with stainless instruments like K- files,H-files. Removal of the microbial organisms from the root canal system is a prerequisite for successful outcome of any root canal treatment (Levine, 1988; Janani et al., 2020).

Use of an effective intracanal medicament will assist in the disinfection of the root canal system. Various chemical agents are incorporated into the root canal for cleaning and shaping the canal which is known as "Biomechanical preparation". The major hurdle in root canal disinfection is the removal of the bacterial biofilm. The only way to achieve optimal removal is by following a proper irrigation protocol and final irrigant activation. Sodium hypochlorite $(\mathrm{NaOCl})$, the most commonly used antibacterial irrigant, in spite of its stupendous tissue dissolving properties, is said to be ineffective against specific bacteria at lower concentrations.

Chlorhexidine (CHX) on the other hand is a broad-spectrum antimicrobial agent, widely used in endodontics for root canal disinfection. Chlorhexidine can be applied during all phases of the root canal preparation, including the disinfection of the operatory field; enlargement of the canals orifices; removal of necrotic tissues before working length determination; in the chemo mechanical preparation prior to the foraminal patency and enlargement; as an intracanal medicament; in the disinfection of obturation cones; for modeling the main gutta-percha cone; in the removal of gutta-percha cones during retreatment; in the disinfection of prosthetic space; among others. (Seltzer, 1978; Leonardo et al., 1999; Noor, 2016; Manohar and Sharma, 2018; Teja and Ramesh, 2019; Siddique et al., 2019).

Once canals are cleaned and shaped, the canals are sealed with gutta percha which is known as obturation. After obturation is completed, coronal seal is done, then tooth preparation and crown cementation are done. In cases with minimal tooth structure loss, veneers can also be used, A veneer is a thin sheet of material placed on the front surface of the tooth, used for aesthetic purposes and protection. It is usually a thin layer of restorative material replacing the enamel (Ravinthar and Jayalakshmi, 2018; Rajakeerthi et al., 2019; Jose and Subbaiyan, 2020). Various clinical trials (Ramamoorthi et al., 2015; Ramanathan et al., 2015; Kumar et al., 2018) and surveys (Nasim and Nandakumar, 2018; Teja et al., 2018; Hussainy et al., 2018) and in vitro studies (Rajakeerthi et al., 2019; Jose and Subbaiyan, 2020) have been conducted by our team in the field of conservative dentistry. Now we are focusing more on retrospective studies. Aim of the study is to find the association of age, gender and teeth distribution in patients undergoing root canal treatment in maxillary anteriors.

\section{MATERIAL AND METHODS}

The study setting was university-based single centered study. A retrospective study was conducted on 988 patients who visited a Private Dental College with complaint of pulpitis who required root canal treatment in maxillary anteriors. Thus, the population includes patients who underwent root canal treatment for 1753 teeth. The advantage of this study was the flexible data that could be obtained immediately and less expensively. The drawback of this study is that there were geographic limitations and the people involved were from an isolated population. The internal validity of the study was carried out by analysing the age and gender of patients who had undergone root canal treatment in maxillary anteriors.

The inclusion criteria were patients requiring root canal treatment in maxillary anteriors. The patient records were reviewed and analysed between June 2019 and March 2020 and the details of patients who had undergone root canal treatment in maxillary anteriors was noted. All available data was included to minimise sampling bias. Cross verification of details was done with the help of photographs and radiographs. Patients of all age groups were included in this study. The data of age and gender of patients who underwent root canal treatment in maxillary anteriors was tabulated. Incomplete and censored data was excluded. Data was entered in a methodical manner. Data was recorded and tabulated on Excel.

Figure 1: The bar graph represents the age distribution of patients. $\mathrm{X}$ axis represents the age of the patient and $\mathrm{Y}$ axis represents the number of patients. Maximum number of maxillary anterior root canal treatment was done in the age group of below 30 years (51\%) (green bar) and the least being patients above 60 years $(6 \%)$ (red bar).

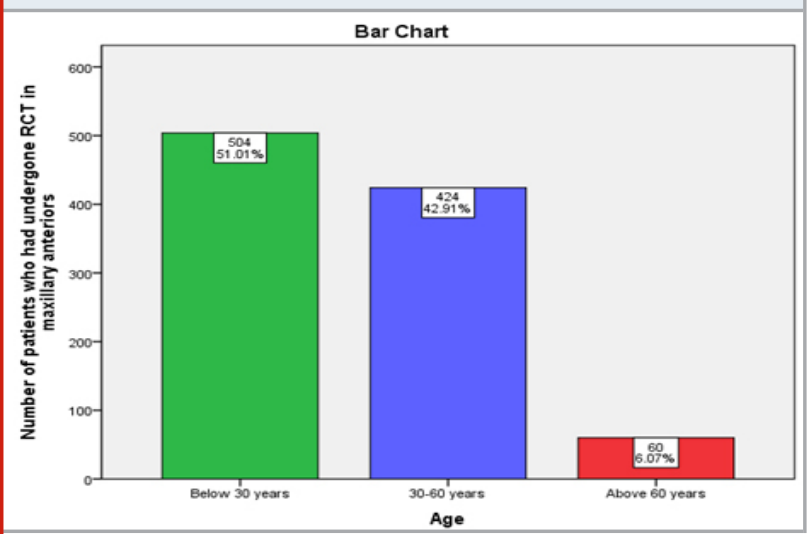

After Excel tabulation, the data was exported to IBM SPSS software [Version 20: IBM Corporation NY USA]. Descriptive statistics were used to calculate correlation between age and gender of patients who underwent root canal treatment in maxillary anteriors. The dependent variable was the treatment done which is root canal treatment in maxillary anteriors. The independent variables were age and gender. Pearson chi square test was done to statistically analyze the data. Pearson chi square test 
was used to identify any significant level of variation of association the significance level was set at 0.05

Ethical Approval: The ethical approval for the retrospective study was obtained from the university (SDC/SIHEC/2020/ DIASDATA/0619-0320).

Figure 2: Bar graph represents the distribution of patients based on gender. $X$ axis represents the gender of patients and $Y$ axis represents the number of patients. Male patients $(52.94 \%)$ (green bar) and female patients $(47.06 \%)$ (blue bar) had undergone root canal treatment in maxillary anteriors

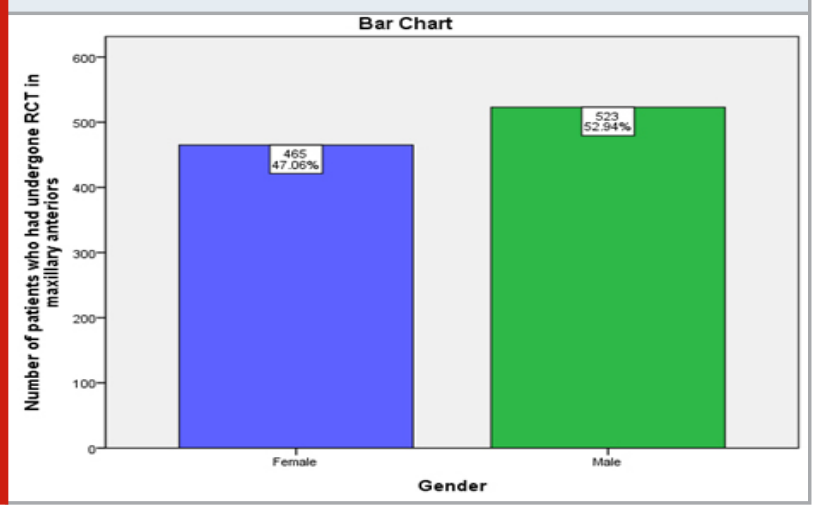

Figure 3: Bar graph represents the teeth distribution of various maxillary anteriors undergoing RCT. $X$ axis represents the tooth number and $Y$ axis represents the number of patients. Maximum number of maxillary anterior root canal treatment was done in $11(23.56 \%)$ (blue bar) and the least being done in $13(10.33 \%)$ (pink bar).

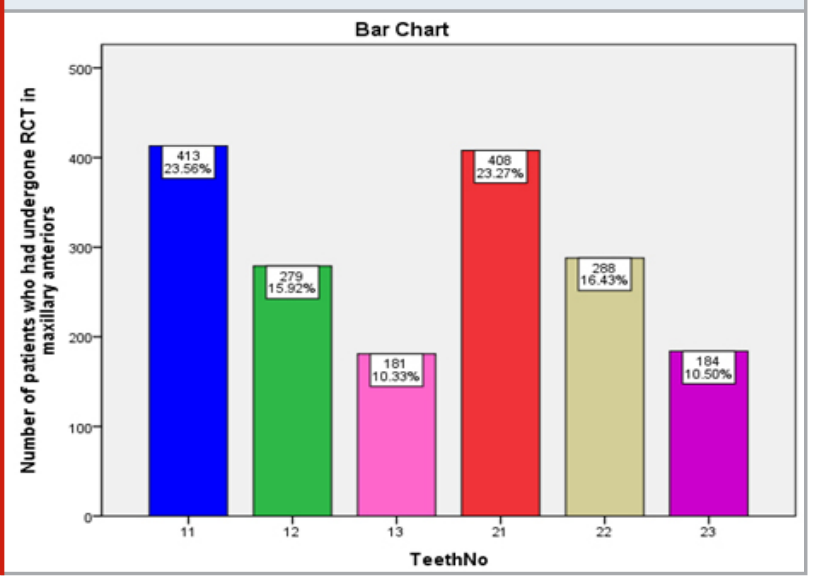

RESULTS AND DISCUSSION

The study included 988 patients and 1753 root canal treatments in maxillary anteriors. Maximum number of maxillary anterior root canal treatments was done in the age group of below 30 years $(51 \%)$ and the least being patients above 60 years $(6 \%)$ (Figure 1). Male patients (52.94\%) and female patients $(47.06 \%)$ had undergone root canal treatment for mandibular premolars (Figure 2). Maximum number of maxillary anterior root canal treatment was done in $11(23.5 \%)$ and the least being done in $13(10.33 \%)$ (Figure 3).

Figure 4: Bar graph represents association between age and tooth number. $X$ axis represents age and $Y$ axis represents number of patients. Most of the RCT was done in the age group of below 30 years, teeth commonly involved was $11(14.49 \%)$ (blue bar) and least was patient above 60 years in $11(0.91 \%)$ (blue bar). Association was found to be statistically significant. Pearson's Chi-square value = 134.015, $\mathrm{df}=10$, $\mathrm{p}$ value $0.00(<0.05)$.

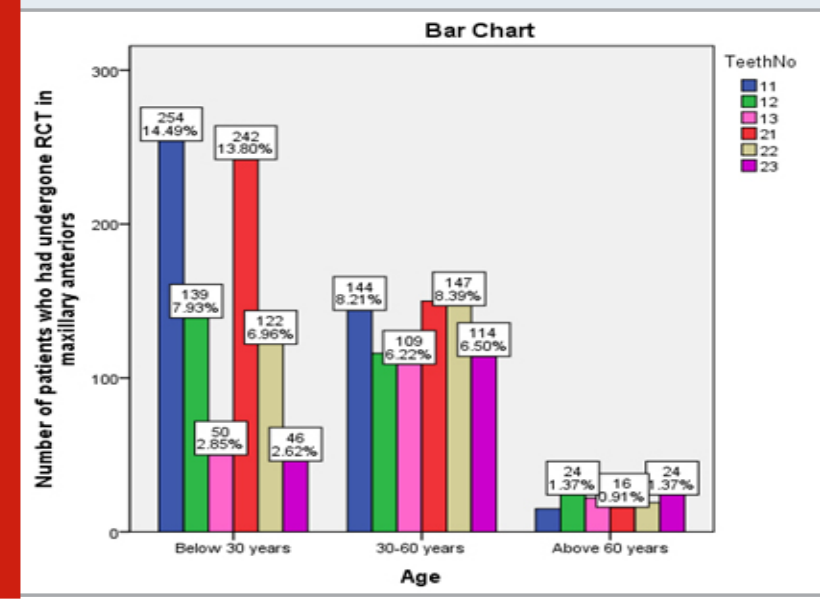

Figure 5: Bar graph showing the association between gender and number of patients undergoing root canal treatment in maxillary anteriors. $\mathrm{X}$ axis represents gender and $\mathrm{Y}$ axis represents number of patients. Most of the RCT was done in male patients in $21(13.92 \%)$ (red bar) and the least being 23 in male patients $(4.16 \%)$ (pink bar). Association was statistically significant. Pearson's Chi-square value $=$ 33.990, $\mathrm{df}=5$, $p$ value $0.01(p<0.05)$

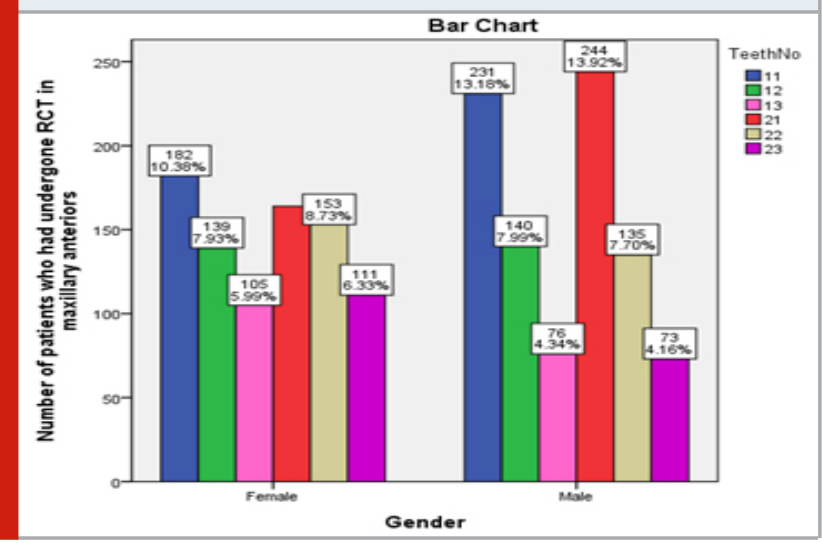

Association between age of the patients and number of patients undergoing root canal treatment in maxillary anteriors, revealed that most of the root canal treatment was done in the age group of below 30 years, teeth commonly involved was 11 and the least was patients above 60 years in $21(0.91 \%)$, hence statistically significant $(\mathrm{p}<0.05)$ (Figure 4). Association between gender of the patient and number of patients undergoing root canal treatment in maxillary anteriors revealed that most of the root canal treatment 
was done in male patients pertaining to tooth number 21(13.94\%) (red bar) and the least being 23 in male patients $(4.16 \%)(\mathrm{p}<0.05)$, hence statistically significant (Figure 5).

Our study assessed the association of age, gender and tooth number of maxillary anteriors. The study group was divided into age groups of below 30 years, $30-60$ years and above 60 years. Age group below 30 years had the highest incidence of root canal treatment in maxillary anteriors while the age group above 60 years had the least incidence for root canal treatment in maxillary anteriors.

More males had reported for root canal treatment in maxillary anteriors than females, this is because young males were more prone to dental disease like dental caries,pulpitis and dental trauma. Similar to our study, Osama et al reported that there was higher incidence in males more than females in his study. In contrast to our study, Augusto et al, reported that the majority of the patients in the study were females when compared to males. And also, Umana et al, the study reported that about half of the patients encountered in the study were females. Ismail et al reported that a total of 2996 RCT cases were seen and $59.8 \%$ of patients were females (Hollanda et al., 2008; Ismail et al., 2008; Osama et al., 2009; Umanah et al., 2012; Rajakeerthi et al., 2019; Jose and Subbaiyan, 2020).

The root canal treatment was more common in the age group below 30 years. Similar to our study, Farret et al reported that the highest incidence of endodontic treatment was performed among patients between 21-29 years age group. Umana et al reported that the highest incidence of root canal disease $(42.7 \%)$ was found in the 20-29 years age group. In contrast to our study, Omitola et al, the study reported that patients in their third and fourth decade have been more commonly observed for dental treatment (Farrell and Burke, 1989; Omitola et al., 2011; Rajakeerthi et al., 2019; Jose and Subbaiyan, 2020).

The root canal treatment was more commonly performed in 11 in our study. Maxillary anteriors are more prone to dental trauma because of its location. Similar to our study, Peak et al reported that of the 406 teeth included in the study, $59 \%(n=241)$ were maxillary teeth and $41 \%(n=165)$ were mandibular teeth. Thirty-two per cent $(n=129)$ were maxillary anterior teeth, $15 \%(n=63)$ were maxillary premolars and $12 \%(n=49)$ were maxillary molars. Maxillary anterior teeth had higher success rates than other tooth types. Ismail et al reported that the maxillary anterior teeth were most commonly treated $(52.6 \%)$. Scavo et al and Al-negrish et al reported that $55.7 \%$ and $77 \%$ of root canal treatment were performed in maxillary teeth respectively (Farrell and Burke, 1989; Al-Negrish, 2002; Peak et al., 2009; Scavo et al., 2011; Rajakeerthi et al., 2019; Jose and Subbaiyan, 2020).

The reason that could have accounted for more root canal treatments being performed in the anterior teeth is the fact that the aesthetic appearance of a patient is influenced at a higher rate by the smile of the patient where there is maximum visibility of the anteriors. It is seen that the anteriors are more prone to dental caries and most importantly trauma. Extraction is not generally preferred by the patient because of the high preference of esthetics among all age groups thus majority of them go in for a root canal treatment. The advantages of the study were availability of data and history of the patients who had reported. The limitations of the study were that the data available was not location specific and the patients belonged to different ethnic populations.

\section{CONCLUSION}

Within the limitations of study, it was found that maximum number of root canal treatment in maxillary anteriors was done in the age group below 30 years $(51 \%)$, with male predominance $(52.94 \%)$ and teeth commonly involved was $11(23.56 \%)$.Association between age of the patient and number of patients undergoing root canal treatment in maxillary anteriors was significant which revealed that most of the root canal treatment was done in the age group of below 30 years and the teeth commonly involved was 11. Association between gender of the patient and number of patients undergoing root canal treatment in maxillary anteriors revealed that most of the root canal treatment was done in male patients pertaining to tooth number $21(13.92 \%)$ which is statistically significant.

Funding: Saveetha Dental College and Hospitals , Saveetha Institute of Medical and Technical Science, Saveetha University.

\section{REFERENCES}

Al-Negrish ARS. (2002). Incidence and distribution of root canal treatment in the dentition among a Jordanian sub population [Internet]. Vol. 52, International Dental Journal. p. 125-9. Available from: http://dx.doi.org/10.1111/j.1875595x.2002.tb00616.x

Al-Rahabi M, Abdulkhayum A. (2012). Single visit root canal treatment: Review. Vol. 2, Saudi Endodontic Journal. p. 80. Available from: http://dx.doi.org/10.4103/16585984.108156

Arya A, Raisingani D, Mital P, Sarraf N. (2018). Endodontic management of maxillary central incisor with two root canals: A case report; Available from: http://www. oraljournal.com/pdf/2018/vol4issue2/PartC/4-2-27-345. pdf

Endodontic treatment of rare anatomical complexity, two canals in maxillary lateral incisor: A case report. Vol. 3, IP Indian Journal of Conservative and Endodontics. 2018. p. 29-30. Available from: http://dx.doi.org/10.18231/24568953.2018.0008

Farrell TH, Burke FJ. (1989). Root canal treatment in the General Dental Service 1948-1987 [Internet]. Vol. 166, British Dental Journal. p. 203-8. Available from: http:// dx.doi.org/10.1038/sj.bdj.4806781

Hollanda ACB, de Alencar AHG, Estrela CR de A, Bueno MR, Estrela C. (2008). Prevalence of endodontically treated teeth in a Brazilian adult population. Braz Dent J.19(4):313-7.

Hussainy SN, Nasim I, Thomas T, Ranjan M. (2018). 
Clinical performance of resin-modified glass ionomer cement, flowable composite, and polyacid-modified resin composite in noncarious cervical lesions: One-year followup. J Conserv Dent. 21(5):510.

Ismail NM, Ismail AR, War WNS. (2008). Root canal treatment in Hospital Universiti Sains Malaysia Dental Clinic--a 5-year retrospective study. Archives of Orofacial Sciences. 3(1):23-8.

Janani K, Palanivelu A, Sandhya R. (2020). Diagnostic accuracy of dental pulse oximeter with customized sensor holder, thermal test and electric pulp test for the evaluation of pulp vitality - An in vivo study. Vol. 23, Brazilian Dental Science. Available from: http://dx.doi.org/10.14295/ bds.2020.v23i1.1805

Jose J, P. A, Subbaiyan H. (2020). Different Treatment Modalities followed by Dental Practitioners for Ellis Class 2 Fracture - A Questionnaire-based Survey. Vol. 14, The Open Dentistry Journal. p. 59-65. Available from: http:// dx.doi.org/10.2174/1874210602014010059

Kumar D, Delphine Priscilla Antony S. (2018). Calcified Canal and Negotiation-A Review. Vol. 11, Research Journal of Pharmacy and Technology. p. 3727. Available from: http://dx.doi.org/10.5958/0974-360x.2018.00683.2

Leonardo MR, Tanomaru Filho M, Silva LAB, Nelson Filho P, Bonifácio KC, Ito IY. (1999). In vivo antimicrobial activity of $2 \%$ chlorhexidine used as a root canal irrigating solution [Internet]. Vol. 25, Journal of Endodontics. p. 167-71. Available from: http://dx.doi.org/10.1016/s00992399(99)80135-6

Levine M. (1988). Root-canal therapy: a means of treating oral pain and infection. Can Fam Physician, 34:1357.

Manohar M, Sharma S. (2018). A survey of the knowledge, attitude, and awareness about the principal choice of intracanal medicaments among the general dental practitioners and nonendodontic specialists. Vol. 29, Indian Journal of Dental Research. p. 716. Available from: http:// dx.doi.org/10.4103/ijdr.ijdr_716_16

Nasim I, Nandakumar M. (2018). Comparative evaluation of grape seed and cranberry extracts in preventing enamel erosion: An optical emission spectrometric analysis. Vol. 21, Journal of Conservative Dentistry. p. 516. Available from: http://dx.doi.org/10.4103/ jcd.jcd_110_18

Noor S, Others. (2016). Chlorhexidine: Its properties and effects. Research Journal of Pharmacy and Technology. 9(10):1755-60.

Omitola OG, Osagbemiro B, Akadiri OA. (2011). Spectrum of diseases and pattern of referral at the Oral Diagnosis Clinic of a tertiary dental center. Niger Dent J. 19(2):66-70.

Osama K, Alia A, Adil S, Qasim J, Sundas AM. (2009). Reasons for carrying out root canal treatment-A study. Pak oral and dent J.29(1):107-10.

Peak JD, Hayes SJ, Bryant ST, Dummer PM. (2001). The outcome of root canal treatment. A retrospective study within the armed forces (Royal Air Force). Br Dent J. Feb $10 ; 190(3): 140-4$.
R R, Rajakeerthi R, Ms N. (2019). Natural Product as the Storage medium for an avulsed tooth - A Systematic Review. Vol. 22, Cumhuriyet Dental Journal. p. 249-56. Available from: http://dx.doi.org/10.7126/ cumudj.525182

Rajendran R, Kunjusankaran RN, Sandhya R, Anilkumar A, Santhosh R, Patil SR (2019). Comparative Evaluation of Remineralizing Potential of a Paste Containing Bioactive Glass and a Topical Cream Containing Casein Phosphopeptide-Amorphous Calcium Phosphate: An in Vitro Study [Internet]. Vol. 19, Pesquisa Brasileira em Odontopediatria e Clínica Integrada. p. 1-10. Available from: http://dx.doi.org/10.4034/pboci.2019.191.61

Ramamoorthi S, Nivedhitha MS, Divyanand MJ. (2015). Comparative evaluation of postoperative pain after using endodontic needle and EndoActivator during root canal irrigation: A randomised controlled trial. Aust Endod J. 41(2):78-87.

Ramanathan S, Solete P. (2015). Cone-beam Computed Tomography Evaluation of Root Canal Preparation using Various Rotary Instruments: An in vitro Study. J Contemp Dent Pract.16(11):869-72.

Ravinthar K, Jayalakshmi. (2018). Recent Advancements in Laminates and Veneers in Dentistry [Internet]. Vol. 11, Research Journal of Pharmacy and Technology. p. 785. Available from: http://dx.doi.org/10.5958/0974360x.2018.00148.8

Ridell K, Sundin B, Matsson L. (2003). Endodontic treatment during childhood and adolescence. A survey of 19 -year-olds living in the city of Malmö, Sweden. Swed Dent J.27(2):83-9.

Scavo R, Martinez Lalis R, Zmener O, DiPietro S, Grana D, Pameijer CH. (2011). Frequency and distribution of teeth requiring endodontic therapy in an Argentine population attending a specialty clinic in endodontics. Int Dent J.61(5):257-60.

Seltzer S. (1978). Pain Control in Dentistry: Diagnosis and Management. Lippincott Williams \& Wilkins;

Setzer FC, Boyer KR, Jeppson JR, Karabucak B, Kim S. (2011). Long-Term Prognosis of Endodontically Treated Teeth: A Retrospective Analysis of Preoperative Factors in Molars. Vol. 37, Journal of Endodontics. p. 21-5. Available from: http://dx.doi.org/10.1016/j.joen.2010.10.005

Siddique R, Sureshbabu NM, Somasundaram J, Jacob B, Selvam D. (2019). Qualitative and quantitative analysis of precipitate formation following interaction of chlorhexidine with sodium hypochlorite, neem, and tulsi. J Conserv Dent. 22(1):40.

Teja KV, Ramesh S, Priya V. (2018). Regulation of matrix metalloproteinase-3 gene expression in inflammation: A molecular study. J Conserv Dent. 21(6):592.

Teja KV, Ramesh S. (2019). Shape optimal and clean more. Saudi Endodontic Journal. Sep 1;9(3):235.

Umanah AU, Osagbemiro BB, Arigbede AO. (2012). Pattern of demand for endodontic treatment by adult patients in port-harcourt, south-south nigeria. Journal of the West African College of Surgeons. 2(3):12. 